\title{
The European Embryonic Stem-Cell Debate and the Difficulties of Embryological Kantianism
}

\author{
Alexandre Mauron and Bernard Baertschi \\ University of Geneva, Switzerland
}

As elsewhere, the ethical debate on embryonic stem cell research in Central Europe, especially Germany and Switzerland, involves controversy over the status of the human embryo. There is a distinctive Kantian flavor to the standard arguments however, and we show how they often embody a set of misunderstandings and argumentative shortcuts we term "embryological Kantianism." We also undertake a broader analysis of three arguments typically presented in this debate, especially in official position papers, namely the identity, continuity, and potentiality arguments. It turns out that these arguments do not support the strong, quasipersonal status accorded to the embryos in these official opinions.

Keywords: embryo, European bioethics, Kantianism, ontology, person

\section{INTRODUCTION}

In recent years, research on embryonic stem cells has been the focus of much ethical controversy as well as of regulatory efforts in many countries and international bodies. To take but one recent example, on July 9, 2003, the European Commission, which is the executive power of the European Union, proposed a set of guidelines that basically "allows for the funding of human embryonic stem cell research in relation to the fight against major diseases" (European Commission, 2003). The most notable restrictions set forth for support of human ES cell research are as follows:

- The cells must only be derived from surplus ("supernumerary") embryos no longer used for IVF treatment, and together with parental consent; this is

Address correspondence to: Alexandre Mauron, Ph.D., Bioethics Research and Teaching Unit, Faculty of Medicine, University of Geneva, Centre médical Universitaire, CH-1211 Genève 4, Switzerland. E-mail: alexandre.mauron@medecine.unige.ch 
actually a requirement of the European Convention on Human Rights and Biomedicine (1997), art. 18.2.

- Only cell lines created before June 27, 2002, may be used.

- Only research of particular importance, with goals not otherwise attainable, ought to be funded.

These guidelines, that only bear upon funding of research by the European Union and not on the legality of such research, are a compromise between the widely divergent views articulated on these issues by national bodies across Europe. These national statements are, in turn, internal compromises produced by various national expert bodies in which ethical arguments, scientific opportunity, and political expediency were mixed in variable proportions.

Even within one body, different commissions sometimes come to divergent conclusions, as exemplified in Germany. The "Enquete Commission" of the German Parliament was in favor of prohibiting embryonic stem cells research altogether, including the import of such cells from foreign countries ("Enquete," 2001). On the other hand, the "National Ethics Council" set up by Chancellor Schröder, produced a more open document, balancing arguments for and against embryonic stem cell research (Ethikrat, 2001). The political debate eventually resulted in a new law leaving the door slightly open to research, by authorizing import of cell lines generated before January 1, 2002 (Vogel, 2002).

There is a common characteristic to all these sorts of documents: few people are ever really happy with them. Critics often deplore what they see as their philosophical shallowness or inclination towards compromise, scientists tolerate them as a workable basis for the research to go ahead under more or less reasonable safeguards, opinion leaders often question the democratic legitimacy of their authors. Few commentators detect any profound and definitive philosophical thinking in these pronouncements. This is not surprising as the logic of political compromise has its own rules, far different from those of the philosophy seminar. Nevertheless, such guidelines are an indispensable meeting point between bioethical arguments and competing societal interests, and provide a useful perspective on the diverse ways in which a given, seemingly universal, ethical issue is framed in different countries. Furthermore, as such guidelines typically claim to go beyond the mere expression of ideological conviction, they are committed to some degree of argumentative quality control.

Within the Central European cultural area, Switzerland has a special place in bioethical discussions. It is strongly influenced by views from other Germanspeaking countries, while being somewhat more open to different philosophical 
influences on account of its greater cultural and linguistic heterogeneity. It is therefore interesting to see how these diverging philosophical and political discourses interacted in the Swiss National Advisory Commission on Biomedical Ethics, of which one of us is a member (Alexandre Mauron).

This Commission produced a consultative document on embryonic stem cell research (Swiss National Advisory Commission, 2002) that was rather influential, at least at the national level. It proposes guidelines that are somewhat more liberal than the recent EU position, or the German law. According to these guidelines, import and research on embryonic cell lines is permitted. There is no requirement that only embryos produced before a particular deadline may be used (a formula actually initiated by the current American administration). In addition, the derivation of cell lines from surplus embryos is possible under conditions which are, however, very restrictive, only because the regulation of IVF in Switzerland is designed to avoid the production of surplus embryos in the first place. The forthcoming legislation on embryonic stem cell research follows the advice of the National Advisory Commission to some extent, but will be contested in a nationwide referendum, so that the final legal situation cannot be predicted.

As mentioned before, the discussions in Switzerland closely reflect those in other Central European countries in content and generally conservative philosophical outlook, with slightly more room for liberal views. Our purpose is to analyze some of these common features and to see how they relate to the Anglo-American understanding of the issues that is dominant in the international bioethics literature.

\section{THE THREE MODELS}

The discussions of the Swiss National Advisory Commission on Biomedical Ethics were strongly influenced by a short paper published in a German medical journal by the physician and ethicist Giovanni Maio (Maio, 2002). This article provides a systematic account of arguments and positions in the debate on the ethical standing of the human embryo as it is played out mostly in the German-language literature.

Maio identifies three broad evaluative models giving an account of the embryo's standing, in which these arguments play a more or less important role: 
(1) the object model

(2) the person model

(3) the respect model

The object model says that the early embryo is basically a thing, a "heap of cells," to which no independent rights or ethically relevant interests are ascribed. At the other extreme, the person model assigns to the embryo a highly protected status akin to that of persons. ${ }^{1}$ This is the model most consistently defended by the Catholic Church and, as Maio noted, implicit in Germany's Embryo Protection Law (Embryonenschutzgesetz).

The respect model is presented as a more reasonable middle ground and assigns to the early embryo a lesser, but nevertheless significant, standing that asserts some form of intrinsic value that commands respect without preventing all forms of killing of early embryos. This model is not new, of course (Meyer \& Nelson, 2001; Robertson, 1995). It is usually identified with a gradualist understanding of the embryo's moral status and represents the "third way" espoused by most committees that have expressed views on this debate on both sides of the Atlantic (Steinbock, 2000). If one looks more specifically at the views of the American authors quoted above, their respect model is clearly distinct from the person model. In their view, respect admits of degrees. Although it prevents any unjustified killing or frivolous use of embryos, it is not incompatible with the destructive use of embryos in the course of scientific research of high value. This is because respect depends on features of the embryo that put it much lower on the scale of moral standing as compared to persons (Meyer \& Nelson, 2001), or because respect for embryos is linked to important symbolic aspects connected with the embryo rather than based on any intrinsic features residing in it (Robertson, 1995). In any case, respect for human embryos can be balanced against other overriding ethical concerns, such as interests of patients who stand to benefit from embryo research.

However, the respect model acquires a very different, and definitely Central-European flavor, whenever the notion of human dignity is allowed to play a central role in justifying and defining the respect due to embryos. Human dignity, rather than human rights and/or interests, becomes the touchstone of the whole debate. Within this particular conceptual framework, either the early embryo has "human dignity" (Menschenwürde) and, as a result, it is protected essentially to the same extent as uncontroversial persons (person model), or it has not, and it is then difficult to escape the liberal conclusions of the object model. Except for a minority of ethicists who explicitly adhere to 
an interest-based ethical theory, this starting point emphasizing human dignity is very widely taken for granted. For instance, the ethics chapter of the technology assessment report on stem cells ordered by the Swiss Council for Science and Technology states that its analysis is based on "the basic ethical principles of respect for human dignity and other recognized principles" (Hüsing et al., 2002, p.126).

"When does human dignity begin?" is the title of countless journalistic pronouncements in the ethics of embryonic stem cell research. Once its strong Kantian roots are recognized, the problem with this view is twofold:

(1) Dignity in the Kantian sense does not admit of degrees. It is basically an all-or-none property. Either $\mathrm{X}$ has dignity, or it has a price and a purely instrumental value. Either $\mathrm{X}$ must never be treated as mere means to an end, or it may sometimes be. Tertium non datur. From a purely formal point of view already, dignity appears ill-suited to function as the basis for a gradual form of reverence for the embryo, as required by the respect model.

(2) To assert that some entity has dignity amounts to prohibiting any balancing of this dignity against other values. Many commentators who insist on using the language of dignity want to have it both ways. They say that the dignity of the embryo is not absolute and can be overridden by other ethical concerns, such as the interests of patients who might benefit from embryonic stem cell research. However, this negates the essential features of dignity in the Kantian sense. Defenders of the respect-model with its typical gradualism and value-balancing features, would be more coherent if they gave up the link with Kantian ethics, but this is culturally painful in the dominant Central-European climate as regards ethics and legal theory.

The extension of dignity from persons to embryos is not a foregone conclusion, to say the least. In fact, the question of whether the concept of Kantian dignity can be applied to anything but rational beings has nothing self-evident about it, and to justify talking about the dignity of a 16-cell blastocyst would require a highly sophisticated ontological and ethical analysis. ${ }^{2}$ But often, especially in journalistic writing or in pronouncements of official bodies, this step is simply assumed and camouflaged by the use of vague terms such as the dignity of "human life." Or one assumes-wrongly - that the Constitution ${ }^{3}$ or the law decides that human dignity start at fertilization, which adds to this muddle a confusion between ethical and legal legitimation. Rarely is the question treated as a genuine problem worthy of sophisticated reflection, at least outside of academic philosophical and theological journals. 


\section{EMBRYOLOGICAL KANTIANISM}

The oversimplifications and misunderstandings around the notion of dignity lead to what we call "embryological Kantianism," to be found all over ethics commission statements, church conference papers, and op-ed pieces. According to this view, the human embryo is protected by the dignity of all "human life," therefore one cannot bargain its right to life against any other value, however important, therefore embryonic stem cell research ought to be banned. This nominally secular position is indistinguishable from the religious defense of the person-model, except that it is less intellectually cogent: embryological Kantians rarely follow through the consequences of their thinking as regards abortion, as religious conservatives typically do. This is why the respect model as used in German and Swiss public discourse, albeit it is usually presented as a "third way," that eschews the extremes and is free from religious commitments incompatible with a secular polity, is actually hard to distinguish conceptually from the person model.

Embryological Kantianism ${ }^{4}$ is present in many other official pronouncements on embryo research, albeit in a weaker form. Many such documents make the distinction between research on spare embryos and research on embryos created ad hoc for that particular purpose. The justification for approving the first and disapproving the second typically relies on the notion of "instrumentalization." But this term is just another term denoting the illegitimate use of some entity as a means only, a consequence of its having dignity. Condemning the instrumentalization of embryos relies on a view that Steinbock rightly argues is "conceptually confused: namely that embryos should be treated as ends in themselves," (Steinbock, 2000). There may be valid arguments for upholding a moral distinction between these two kinds of embryo research (Outka, 2002) but the traditional "instrumentalization" argument is not a sound one.

It is striking how different the Central European respect model is to the American views presented earlier, especially the one articulated by John Robertson (Robertson, 1995). This variant of the respect model is not affected by the problems of embryological Kantianism, because in asserting that the embryo is an important symbol of human life, he points to a connection between the embryo and a general feeling of reverence for life that deserves to be fostered in society, not to the embryo's intrinsic developmental potential. Respect, in this sense, is in the eyes of the respecter. It is a relational property, not a monadic one. On the contrary, European discussions always emphasize that 
"human dignity" is an intrinsic property that does not depend on the "subjective" attitude of granting it or refusing it to somebody or something. This is not to say that Anglo-Saxon writers are insensitive to the ontological dimension of the problem. Nevertheless, and unlike what we see on the Continent, they tend to articulate such ontological considerations with valuations that originate from social processes.

Several Continental authors are well aware of the problematic nature of the arguments behind embryological Kantianism. Indeed some theologians that broadly subscribe to the Kantian tradition and to the primacy of "human dignity" in these debates are nevertheless more sensitive to the argumentative weaknesses we have mentioned. For instance, Johannes Fischer, a member of the Swiss National Advisory Commission on Biomedical Ethics, repeatedly raised the question of whether Menschenwürde meant the dignity of human life generally or the dignity of a human being. He criticized the view commonly referred to in the English language literature as the "sanctity-of-life" view as both un-Christian and un-Kantian. In contrast, he maintained that "human life is worthy of protection to the extent that it is the life of a human being, whose integrity one has a duty to respect" (Fischer, 2001). This had the effect of refocusing the debate in the Commission on the greater or lesser validity of arguments assigning to the embryo the protection and standing that accrues to what we have called "uncontroversial persons." Since these arguments are themselves controversial, and in our opinion clearly invalid in their common form, it is not surprising that the Commission's report came out as somewhat more liberal than would have been assumed from the generally conservative bioethical climate in Switzerland. To these arguments we now turn.

\section{THE THREE ARGUMENTS}

Maio identifies four arguments as regards the status of the embryo:

(1) the potentiality argument

(2) the identity argument

(3) the continuity argument

(4) the "species-belonging" argument.

In their canonic form, these arguments are usually presented as supporting a "strong" standing of the human embryo, more or less identifying its moral standing to that of what we will call "uncontroversial persons", that is, persons 
like you and us, whose personal standing is not in dispute. The first three arguments will be examined in this paper.

The three arguments analyzed here all are prima facie arguments in favor of the person-model. More precisely, they are traditionally advanced to defend the "zygote-as-person" thesis, an ontological identification of the early embryo with the person it may become (Baertschi, 1995; Mauron, 2001, 2002). This ontological thesis, if true, would give a high degree of plausibility to the ethical thesis according to which one ought to treat early embryos like persons ever since fertilization. It is sometimes asserted that these three arguments are clearly correct and that whatever controversy is left only concerns the extent of their ethical implications (see Hüsing et al., 2002, pp.133-134). In fact, all are questionable and actually false in their more popular formulations.

\section{INDIVIDUALITY}

"I once was a blastocyst and that blastocyst was already me." Most of us can readily subscribe to this statement. Only if we have a monozygotic twin brother or sister does this assertion raise logical difficulties. Because this statement expresses a strong, and seemingly straightforward, intuition, it is usually taken to prove directly the kind of ontological identity between the early embryo (or even the zygote immediately resulting from fertilization) and uncontroversial persons, an identity that makes the person model so compelling at first sight. But how are we to deal with the case of twins? They cannot truthfully make the above statement, as discussed extensively by Mauron (2002). Each of a pair of monozygotic twins is a distinctive person; if they were both to assert their numerical identity to the zygote they originated from, that assertion would contradict the fact that it is a single zygote that gave rise to both. Or to put it the other way round: if a single zygote gives rise to two numerically separate individuals, that zygote cannot—by the transitivity of identitybe numerically identical to both of them. Therefore, in the case of monozygotic twins, there has to be a time, later than fertilization, at which an additional individual arises that is numerically identical to the person it eventually becomes.

A common objection points out the exceptional nature of twinning and falls back on the statement that "usually" fertilization is the starting point of a new individual, that is congruent with an eventual person. But this objection misses the point of the twinning problem. The thesis that the formation of a new zygote and a new diploid genome is, by its very nature, the biological 
substrate of new personal identity (i.e., the numerical identity of a new person) is falsified by any clear-cut exception, no matter how rare. The logical contradiction mentioned above and arising in the case of monozygotic twins is such an exception. Once this is recognized, it remains true of course that many zygotes appear to be numerically identical to the person they become, but that identity is apparent and not real. At that point, there is no reason left to identify the origin of individuality with fertilization. In other words, although fertilization is important in establishing genomic individuality (the property that sets a particular diploid genome apart from any other), the latter is a necessary but not sufficient condition for determining the numerical identity of a person (several other considerations suggest that the earliest biological event that may fit the bill is gastrulation, see Smith \& Brogaard, 2003).

One sometimes hears another objection, according to which the fact that the zygote can give rise to one or more human individuals means that it has "even more dignity" or entitlement to protection. This objection begs the question in assuming that dignity accrues to any being that can somehow generate a person or persons, yet that is precisely what is being questioned by doubters on the "zygote-as-person" thesis. As we will discuss later, one minimal and uncontroversial aspect of personhood seems to be the notion that a person is the same person through time, that is, transtemporal identity. A "generous" interpretation of dignity would then include any being that is transtemporally identical to an uncontroversial person. On that account, a sperm is not included since it is not identical with a person the existence of which it helps to bring about. One reason is that it needs to be combined with a particular ovum before it has the sort of genomic distinctiveness that is the necessary (but not sufficient) condition for personal identity. What about a zygote or early embryo, then? Although it has a distinctive genome that is identical with the genome of a future person, it does not have the kind of transtemporal identity that is sufficient to identify it to an uncontroversial person, for whatever distinctive genomic (or non-genomic, for that matter) characteristics an early embryo has, they are not incompatible with several distinctive persons originating from it.

\section{CONTINUITY}

An embryo has the capability to become one or several persons. It therefore has the capability to become a person, rather than something else. This brings us to the potentiality argument examined further down, and which is based on 
what the embryo will become rather than on what it is. Yet there is still another actual property of the embryo that might be considered of moral relevance, namely continuity. "I once was a blastocyst": the idea suggested by this assertion is that between the embryo I was and the person I became, there is a temporal continuity such that at no time after fertilization is there any clear-cut break. All the way to the fully constituted person, and until death, from beginning to end, it is the same individual, the same being that persists.

From what we said about identity, the flaw in this argument immediately appears. Strictly speaking, it is not true that $I$ was once a blastocyst, since there is no trans-temporal identity between an embryo and an ensuing person. There is not a "strong," identity-saving, continuity between an embryo and a person as evidenced by the possibility of an identity-breaking singularity during the first phases of development (i.e., as long as twinning is possible). Of course, there is an apparent temporal and topological continuity all the way through prenatal development, but this is without relevance as regards individuality.

It is not surprising that this apparent continuity can hide several breakpoints, since this is in fact the case with many continuities in nature. Seasons are continuous, yet they are separated by solstices and equinoxes. There is a continuity between the seed and the plant, yet germination defines a breakpoint. There is a continuity between the larva and the butterfly, yet the various stages of larval and pupal development are easily conceived of as discrete steps. Furthermore, such steps need not be instantaneous: a process with fuzzy limits represents a break-point just as well as a sharply defined border. In a sense, the continuous and the discrete are two sides of the same coin. Between an embryo and a person, there is continuity and there are discrete breaking points, such as the one manifested by twinning. Each of a pair of monozygotic twins can truthfully assert to be continuous with a single common zygote, and yet they are not identical individuals for all that (see Mauron, 2002).

These comparisons show that the continuity argument is rather vague and based on an intuitive notion of continuity as mere absence of visible and apparent breaking points, without actually spelling out with a significant breaking point would be like. However, several alternative readings of the argument are possible. A weaker one would be that if I am temporally-topologically continuous with the embryo I originated from, then this embryo and myself have certain properties in common. Obviously, from the fact that A and $\mathrm{B}$ have a common property, one cannot infer that they are the same individual, nor that they are beings of the same nature, but it does follow that they 
are not completely foreign to each other. If A and B are an embryo and a particular person respectively, to assert that they are continuous means that $\mathrm{A}$ has the capability to become B. This is actually nothing else but the potentiality argument and we can now see that in its only satisfactorily precise form, the continuity argument is actually identical to the potentiality argument.

\section{POTENTIALITY}

As we have mentioned, the potentiality argument refers to what the embryo will be rather to what it is. This is morally relevant insofar as a being which is not a person now, but which will be one in the future, should not be treated in the same way as one which will never be a person, such as an animal, for instance. This latter point is also implied by the argument. Once we take a closer look, however, it appears that the argument is poorly spelled out: an embryo is a potential person even if it will never become a person, for instance, because it will be destroyed or used in an experiment. It is a potential person because it can become a person. Strictly speaking, the potentiality argument does not rely on the embryo's future, but on what the embryo is now, namely a potential person.

Therefore, to state that A is a potential B is to state that A possesses the dispositional property of becoming $\mathrm{B}$ (a potentiality is a disposition). This disposition to become B, A has it now. For instance, if we say that silica sand is potential glass, we mean that it has the actual capability to become glass, a property that sugar, for instance, does not have. The same applies to the embryo: if we say that it is a potential person, we imply that it already has something that allows it to become a person. What that present property actually consists of (the diploid genome, the soul, etc.) is irrelevant to the argument. What counts is that there has to be such a capability, thanks to which the embryo is a potential person rather than any random collection of cells.

But is it a potential person or a person? If an embryo presently has the property that allows it to become a person, are we not justified to say that it is a person already? Sand is not yet glass, but one only needs to heat it sufficiently for the transformation to occur, without addition of any constitutive property. Similarly, one only has to plant and water an acorn for it to become an oak tree. This is where the serious confusions begin. They stem from neglecting a series of indispensable distinctions needed to refine the often used notions, of Aristotelian origin, of active and passive potency. 
The first concerns two types of dispositions mentioned above, namely potentialities and capabilities. Briefly, potentiality is about being, capability about doing (or undergoing). Sand is potentially glass, and glass has the capability to break (it is fragile). Does that mean that we confused potentiality and capability when we said that sand has the capability to become glass? No, since we were not referring to a capability of doing but a capability of becoming. Therefore potentiality is a capability of becoming, and this way of speaking makes good sense, for to become something, on must possess the power of doing whatever is necessary to become that thing. Therefore:

- "A is a potential B" (= A has the capability to become a B) implies that A is not a $B$ in actuality.

- In contrast, "A has the capability to do C" implies that A is already all that it needs to be in order to accomplish $\mathrm{C}$; it just happens not to do $\mathrm{C}$ at present.

Glass is fragile, it therefore has the capability to break (it can break), but this is true even if no breaking is happening now (unless one is toasting the Russian way, one usually tries to prevent the breakage of glass from actually occurring); similarly, if someone has the capability to speak English, this does not mean that this person is presently speaking English, but that he or she could do it without acquiring anything that it does not possess already. In contrast, it is wrong to say that sand is fragile and that an embryo has the capability to speak English; one can merely say that they will acquire them, once they will become glass and a person, respectively (they only have the capability of becoming them). This confusion is apparent whenever one hears that every human being in utero already has all the "capabilities" that belong to humans, including those to learn whatever will be necessary to live the life of a person. That so many things can go wrong on the road to personhood is evidence that this lumping together of potentialities and capabilities of doing does not match reality.

This brings us to a first invalid reason why it is often asked to treat the embryo like a person, even while faintly admitting that it is not one, namely the confusion between potentiality and capability. Once the two are clearly distinguished, it becomes clear that a potential $\mathrm{B}$ is not a $\mathrm{B}$ and that an embryo is not a person. It is not surprising that official Catholic Church doctrine, which is in this case more lucid that many ethics committees, attempts to maintain that the embryo is an actual person, and is not satisfied with the statement that it is a mere potential person: from its point of view, the embryo 
possesses a human soul already, and has all characteristically human capabilities that are manifest in its already being a live human being (but we have seen the problem that this line of thinking entails as regards the concept of capability).

From the starting point that the embryo is only a potential person, Benn has developed a well-known and often quoted argument:

If $A$ has rights only because he satisfies some condition $P$, it doesn't follow that $B$ has the same rights now because he could have property $P$ at some time in the future. It only follows that he will have rights when he has $P$. He is a potential bearer of rights, as he is a potential bearer of $P$. A potential president of the United States is not on that account Commander-in-Chief. (Benn, 1984, p.143)

Since an embryo is a potential person, it is not a person and does not possess the moral and legal prerogatives of persons. It is again clear that the question of the status of the embryo is important because of its moral impact, here expressed in terms of rights. We will come back to his point, but for the time being, we wish to show that Benn's argument, albeit based on a correct distinction between potentiality and capability, is too quick in concluding as it does. In fact, the comparison it uses, that is, between potential president and potential person is not really relevant. Two different sorts of potentiality are involved, and further distinctions are needed along two axes (Baertschi, 1995, pp.193-195):

(1) The relevance of potentialities. Every U.S. citizen is a potential U.S. president, but for the vast majority of U.S. citizens, this is irrelevant since becoming president is not part of their realistic prospects, their life plans, and their identity as persons. In contrast, becoming a person is very important. Think of prospective parents watching the ultrasound image of their future child: it might become an artist, a dentist, or an ethicist, but most importantly, it ought to become a person. Therefore, from the fact that any citizen cannot require to be treated as a president, it does not necessarily follow that any embryo should not be treated as a person, or at least with the respect due to persons.

(2) The source of the actualization of potentialities (Byrne, 1988, p. 95; Ford, 1988, p. 110). To become U.S. president, one must be elected, to become a person, it is usually sufficient to undergo normal development. Certain potentialities are actualized externally, others internally. The latter have more 
ontological relevance in the sense that they point to the possession of a causal power or teleology (Callahan, 1988, p. 50), that is absent in the first.

This also allows us to distinguish the potentiality of a gamete and of an embryo. In a sense, they are both potential persons, but this potentiality is less fundamental for the gamete (especially the sperm) than for the embryo given their natural destiny, and the actualization of the gamete's potential requires more external intervention.

At this point we can say that an embryo is not a person but that a potential person is already something important. For the embryo, it means to possess a basic and intrinsic power, the capability to become a person or persons. This is a weakened form of the continuity argument, but it appears more solid, and strong enough to justify giving a rather elevated status to the embryo.

Or so it seems. In fact, this formulation is still not satisfactory because it omits a further essential distinction about potentiality. For A to be a potential $\mathrm{B}$ can be understood in two ways, for this expression can have two quite different meanings (Baertschi, 2004; Joyce, 1988, p. 206).

(1) An expressive meaning. "A is a potential B" means that A has the capability to realize its implicit nature of B (in other words: its implicit nature, which is that of a B). For instance, when we say that environmental pollution is a source of potential problems for humankind, we mean that the roots of these problems are already present, yet hidden, and if we only wait, the problems will become manifest. This is the most common understanding of potentiality, but another meaning is important:

(2) A causal meaning. "A is a potential B" means that A has the capability to cause the existence of B (or to be a causal factor of B's existence). This is what is meant when saying that sand is potential glass and a gamete a potential person.

What about an embryo then? Is it a potential person in the sense that it has the capability to realize its implicit nature of person or in the sense that it has the capability to cause a person to exist? Considering continuity as well as the common usage of the term potentiality may well induce us to think of the expressive meaning but this is clearly wrong. As mentioned when examining the identity argument, an embryo is not identical to the fetus and person that originates from it: rather, they should be seen as two individuals connected by a causal relation.

Another way to make plain that the expressive meaning of potentiality is not relevant here is to consider some basic and non-controversial aspects of 
the nature of a person. To be a person is (in a sense not further explored here) to be somebody rather than something, but also to be somebody definite rather than to be somebody and at the same time possibly somebody else. A definite trans-temporal identity is a truly rock-bottom requirement for the nature of person, ${ }^{5}$ but that is precisely what the early embryo lacks, even in an implicit or "germinal" form. ${ }^{6}$ Therefore there is no hidden "nature-of-person" present at this stage, to be merely uncovered by further prenatal development.

Thus we find a second invalid reason to consider an embryo as a person, namely the confusion of the causal and expressive meaning of potentiality. As soon as these are distinguished, it becomes plain that an A who is a causally potential B cannot be a B and that an embryo cannot be a person.

In summary, if we cannot generally assert that an embryo and a fetus (and a person) are one and the same individual, then asserting their continuity has little definite meaning. In contrast, the potentiality argument is of some value if interpreted correctly. It should be understood as follows: when we state that an embryo is a potential person, we mean that it has the capability to cause the existence of a fetus and a person, that this capability is basic to the kind of being it is, and that it is a potentiality that is to a large extent actualized internally.

At this point, we have two kinds of ontological considerations that seem relevant for assessing the moral standing of the embryo. Our analysis of the identity argument shows it to be instead a non-identity argument, pointing to a low moral standing of the early embryo. The potentiality argument is not a truly independent argument, since it turns out to be dependent on a proper analysis of identity. Nevertheless, it tells us that the embryo, while not a person, is a central causal factor in a future person's existence. This suggests that the embryo has a moral standing that is significant (more than a "mere heap of cells"), but still quite modest. Be that as it may, we should bear in mind that such ontological arguments severely underdetermine any final moral conclusions we may wish to make. We now turn to these moral consequences.

\section{CONCLUSION}

In Europe, relatively few people, outside committed Catholics, are ready to assert that blastocysts are persons and to commit themselves to all the consequences, such as, for instance, devising adoption schemes for frozen spare embryos. On the other hand, few people are ready to say that early embryos 
are mere things either, since this view sounds cold and heartless and is imaginatively associated with the unfeeling scientist, intent on pursuing his (of course it's a "he") scientific goals single-mindedly, whatever the moral costs. Therefore, there is an enormous political premium set on finding a "third way," namely the respect model, as we have seen.

How would such a model function considering the arguments we have harvested from the ontological field? They certainly justify saying that the embryo is neither thing nor person, given its basic properties and capabilities. What is the appropriate ethical attitude towards it then? A form of respect, most would say. That statement is not enormously enlightening, however, since respect refers to a moral attitude expected towards many objects. Physicians ought to respect patient autonomy, citizens ought to respect the law, competitors in sports ought to respect each other, boys ought to respect girls, the list is indefinite; more precisely, as regards our problem, the respect model appears as vague because it is unclear on:

(1) What the basis for respect is.

(2) What respect actually prohibits one from doing.

(3) How much respect exactly is owed to the very early embryo and how that measure of respect is to be weighed against the interests of patients.

On the other hand, what we have established so far provides partial answers to these questions: if we respect a being, it is both because of what we are and because of what it is. For the embryo, that means: because of its capability to cause a (or more) person(s) to exist. But one must add that it is not a person, whatever respect is due to it is less than the respect due to persons. We therefore face the following choice:

(1) Decide that the embryo is not worthy of a great deal of respect after all, or that if it is, the sort of respect involved is more concerned with socially valuable feelings of piety for human life than with any inherent property of the embryo itself;

(2) Decide that the potentiality argument has significant ethical merit, on account on the "inner" nature of the drive that leads from the early embryo to a person or persons.

Deciding whether option 1 or 2 is correct is surprisingly difficult, and will not be discussed in detail here. Suffice it to say that the argument would need to take on board contemporary findings about the reprogramming of somatic cell nuclei by nuclear transplantation in an oocyte, as evidenced by the very 
possibility of mammalian cloning (Juengst \& Fossel, 2000). The potentiality restored to a somatic cell by nuclear transplantation is not perfect, as evidenced by the anomalies of most born clones, but it does suggest that whatever is usually missing in a somatic cell nucleus to direct the full normal development of a new individual has to do with the incomplete genetic reprogramming that occurs during nuclear transfer as opposed to normal gametogenesis, and not with the lack of some mysterious intrinsic property present only in the zygote nucleus. ${ }^{7}$ In other words, even if a reprogrammed somatic cell nucleus is not perfectly identical with the nucleus of a natural zygote, it may not be very different in terms of potentiality.

The overworked distinction between "pluripotentiality" and "totipotentiality" notwithstanding, we therefore seem perilously close to having to grant a high status to any somatic cell if we give it to the zygote. Of course the source of the actualization of potentiality is different in the two cases-external versus internal-but the closeness of these cases must induce us to downplay the importance of potentiality as applied to these issues. Therefore, if we discount the extreme vitalistic option of giving the highest respect to every somatic cell (Lachmann, 2001), it becomes quite plausible to say that the interest of patients to benefit from medical progress easily trumps respect for the embryo, except for symbolic restrictions of cultural or religious origin which are not connected to the intrinsic status of the embryo, that is, with what it is, ontologically speaking.

This conclusion is clearly at variance with the majority opinion in European institutional bioethics, as we have seen. To some extent, this discrepancy expresses the different criteria governing philosophical truth and political truth. In addition, it suggests that to really think these complex issues through is rather damaging to received ideologies such as "embryological Kantianism." Since such ideologies embody strongly held taboos, their questioning raises often shrill reactions. Nevertheless, as Central European bioethics reaches maturity, it can be expected that these questions will be aired and discussed in a more scholarly and serene way.

\section{ACKNOWLEDGMENTS}

This article is part of a project of the Centre lémanique d'éthique, jointly supported by the Fondation Louis-Jeantet de médecine and the Fondation Leenaards. Alexandre Mauron is a member of the Swiss National Advisory Commission on Biomedical Ethics. Bernard Baertschi is a member of the Swiss Ethics Committee on Non-Human Gene Technology. The views expressed herein do not necessarily reflect those of either Commission. 


\section{NOTES}

1. The notion of human person used here is shaped by the Kantian tradition that emphasizes special properties, such as rationality and autonomy. These properties mark persons apart form other natural beings - such as animals for instance, a point explicitly made by Kant (1974, part I, bk I, § 1) - and confer to persons a specific dignity. The latter concept is in turn closely connected with the notion of an intrinsic worth that is incommensurable with a purely instrumental value or a mere price. In contrast, "human being" is used here to refer to any form of biological organism belonging to the species homo sapiens.

2. An argumentation doomed to fail, unless one abandons the Kantian model.

3. In Germany, innumerable statements refer to art. 1 and 2 of the Constitution (protection of human dignity) as being the final word on the issue, without actually constructing any recognizable argument.

4. The Kantian credentials of "embryological Kantianism" are questionable not just because Kant did not take a stand "on the status of the embryo" (an obvious biological anachronism), but because it is difficult to read into Kant's writings any notion of a sliding scale of dignity, on which to place different beings at higher or lower levels.

5. This is the case whether this identity is conceived as "strong" or "weak" (Parfit, 1984, pp. 202-204).

6. Among the defenders of the personhood of the early embryo, the expressive understanding of potentiality often corresponds to a strong intuition that matches the "blueprint" concept of the genome: since the new diploid genome is established at fertilization, a popular genomic reductionism tempts many to think that this genome is merely actualized and "unwrapped", as it were, during development to give a definite individual and person (Mauron, 2002).

7. In fact, recent experiments have shown that mice can be derived by nuclear transfer from terminally differentiated lymphocytes (Hochedlinger \& Jaenisch, 2002). Because of the unique genetic markers provided by the rearranged immune-receptor genes of mature lymphocytes, these cloning experiments provide the first definite proof "that terminally differentiated cells can remain genetically totipotent" (Hochedlinger \& Jaenisch, 2003, p. 278).

\section{REFERENCES}

Baertschi, B. (1995). La valeur de la vie humaine et l'intégrité de la personne. Paris: PUF.

Baertschi, B. (2004). Du bon usage de la règle d'Or: Richard Hare et la question de l'avortement. Recherches sur la philosophie et le langage. (forthcoming).

Benn, S. I. (1984). Abortion, infanticide, and respect for persons. In: J. Feinberg (Ed.), The problem of abortion. (pp. 135-144). Belmont, CA: Wadsworth.

Byrne, P. (1988). The animation tradition in the light of contemporary philosophy. In: G. R. Dunstan and M. Seller (Eds.), The status of the human embryo (pp. 86-110). London: King Edward's Hospital Fund for London.

Callahan, D. (1988). The "beginning" of human life. In: M. Goodman (Ed.), What is a person? (pp. 29-55). Clifton NJ: Humana Press.

"Enquete" Commission, German Bundestag. (2001). Enquete-Kommission hält zwei Wege für Regelung des Imports embryonaler Stammzellen für möglich [On-line]. Available: 
http://www.bundestag.de/gremien/medi/med_prs/medprs_113.htm(accessed Aug. 9, 2003).

Ethikrat (2001). Nationaler Ethikrat: Stammzellenforschung [On-line]. Available: http:// www.ethikrat.org/themen/stammzellforschung.html (accessed Aug. 9, 2003). .

Europe, Council of Europe. (1997). Convention on Human Rights and Biomedicine [On-line]. Available: http://conventions.coe.int/Treaty/EN/Treaties/Html/164.htm (accessed Aug. 9, 2003).

European Commission (2003). European Commission proposes strict ethical guidelines on EU funding of human embryonic stem cell research [On-line]. Available: http://europa.eu.int /rapid/start/cgi/guesten.ksh?p_action.gettxt=gt\&doc=IP/03/969|0|RAPID\&lg=EN\&display (accessed Aug. 9, 2003).

Fischer, J. (2001). Pflicht des Lebenschutzes nur für Menschen. Eine theologische Betrachtung der Embryonenforschung. Neue Zürcher Zeitung. 12 September 2001, p. 8.

Ford, N. M. (1988). When did I begin? Cambridge: Cambridge University Press.

Hochedlinger K. \& Jaenisch R. (2002). Monoclonal mice generated by nuclear transfer from mature B and T cell donor cells. Nature, 415, 1035-1038.

Hochedlinger K. \& Jaenisch R. (2003). Nuclear transplantation, embryonic stem cells, and the potential for cell therapy. New England Journal of Medicine, 349, 275-286.

Hüsing, B., Engels, E.M. Frietsch R., Gaisser, S., Menrad, K., Rubin-Lucht, B., \& Schweizer, R.J. (2002). Menschliche Stammzellen. Berne: Centre for Technology Assessment.

Joyce, R. (1988). Personhood and the conception event. In: M. Goodman (Ed.), What is a person? (pp. 199-211). Clifton, NJ: Humana Press.

Juengst, E. \& M. Fossel (2000). The ethics of embryonic stem cells-now and forever, cells without end. Journal of the American Medical Association, 284, 3180-3184.

Kant, E. (1974). Anthropology from a pragmatic point of view. Dordrecht: Kluwer.

Lachmann, P. (2001). Stem cell research - why is it regarded as a threat? An investigation of the economic and ethical arguments made against research with human embryonic stem cells. European Molecular Biology Organisation Reports, 2, 165-168.

Maio, G. (2002). Welchen respekt schulden wir dem embryo? Dtsch Med Wochenschr, 127, $160-163$.

Mauron, A. (2001). Essays on science and society. Is the genome the secular equivalent of the soul? Science, 291, 831-382.

Mauron, A. (2002). Genomic metaphysics. Journal of Molecular Biology, 319, 957-962.

Meyer, M. J. \& L. J. Nelson (2001). Respecting what we destroy. Reflections on human embryo research. Hastings Center Report, 31, 16-23.

Outka, G. (2002). The ethics of human stem cell research. Kennedy Institute of Ethics Journal, $12,175-213$.

Parfit, D. (1984). Reasons and persons. Oxford: Oxford University Press.

Robertson, J. A. (1995). Symbolic issues in embryo research. Hastings Center Report, 25, 37-38.

Smith, B., \& B. Brogaard (2003). Sixteen days. Journal of Medicine and Philosophy, 28, 45-78.

Steinbock, B. (2000). What does "respect for embryos" mean in the context of stem cell research? Womens Health Issues, 10, 127-130.

Swiss National Advisory Commission on Biomedical Ethics. (2002). On research with embryonic stem cells. Berne [On-line]. Available: http://www.nek-cne.ch/de/pdf/SN3_Stammz_de.pdf (accessed Aug. 9, 2003).

Vogel, G. (2002). Regulations constrain stem cell research across the globe. Science, 297, 924. 
